\title{
Análise de Crescimento do Capim-Marandu Submetido a Doses de Nitrogênio ${ }^{1}$
}

\author{
João de Deus Gomes dos Santos Junior², Francisco Antonio Monteiro³ ${ }^{3}$ José Lavres Junior4
}

RESUMO - Objetivou-se, neste estudo, avaliar o crescimento da Brachiaria brizantha (A. Rich.) Stapf. cv. Marandu, submetida a doses de nitrogênio $(\mathrm{N})$ na solução nutritiva $\left(28,112\right.$, 210, 294 e 378 mg/L, na proporção constante de 70\%:30\% entre N-NO ${ }_{3}^{-}$e N$\mathrm{NH}_{4}{ }^{+}$), em diferentes idades de crescimento (21, 28, 35, 42, 49 e 56 dias após a emergência). O experimento foi conduzido em casa-devegetação, em solução nutritiva, e utilizando sílica como substrato. O delineamento experimental foi o de blocos completos ao acaso, com quatro repetições, em arranjo fatorial 5x6. As doses de $\mathrm{N}$ e as idades de crescimento interagiram significativamente em todos os atributos de crescimento do capim-marandu, com exceção da taxa de assimilação líquida (TAL). Constatou-se valor máximo para a taxa de crescimento relativo (TCR) e taxa de crescimento absoluto (TCA), respectivamente, de 0,25 g/g.dia à idade de 28 dias, com o $\mathrm{N}$ na solução em 378 mg/L e 3,68 g/dia, aos 56 dias de crescimento, com a dose de $\mathrm{N}$ de $378 \mathrm{mg} / \mathrm{L}$. Aos 21 dias de crescimento, verificaramse valores máximos de 2,16 dm²/g para a razão de área foliar (RAF), com a mais alta dose de N, 0,48 g/g para a razão de massa foliar (RMF), com N na dose de $294 \mathrm{mg} / \mathrm{L}$ e de 5,14 dm²/g para a área foliar específica (AFE), com o suprimento de $\mathrm{N}$ na solução em $378 \mathrm{mg} / \mathrm{L}$.

Palavras-chave: área foliar específica, Brachiaria brizantha, razão de área foliar, razão de massa foliar, taxa de assimilação líquida, taxa de crescimento relativo

\section{Growth Analysis of Marandugrass in Response to Nitrogen Rates}

\begin{abstract}
This research was conducted with the objective of determining growth of Brachiaria brizantha (A. Rich.) Stapf. cv. Marandu under nitrogen $(\mathrm{N})$ rates $\left(28,112,210,294\right.$ and $378 \mathrm{mg} / \mathrm{L}$, where $\mathrm{N}-\mathrm{NO}_{3}{ }^{-}: \mathrm{N}^{-\mathrm{NH}_{4}}{ }^{+}$of $70 \%: 30 \%$ proportion was kept constant) and growth ages (21, 28, 35, 42, 49 and 56 days after seedling emergence). The experiment was carried out in greenhouse conditions, with nutrient solution and using ground quartz as substrate. The experimental design used was a complete randomized block design, with treatments arranged in a 5x6 factorial, with four replications. Nitrogen rates and growth ages interaction was significant for all growth attributes of Marandugrass, except for the mean net assimilation rate (NAR). The results showed that the maximum values for the relative growth rate (RGR) and absolute growth rate (AGR) were $0.25 \mathrm{~g} / \mathrm{g}$.day and that was observed at 28 days with $\mathrm{N}$ rate at $378 \mathrm{mg} / \mathrm{L}$, and $3.68 \mathrm{~g} /$ day at 56 days associated to $\mathrm{N}$ rate at $378 \mathrm{mg} / \mathrm{L}$, respectively. At 21 days of growth, occurred maximum values of $2.16 \mathrm{dm} / \mathrm{g}$ at the highest $\mathrm{N}$ rate for leaf area ratio (LAR), of $0.48 \mathrm{~g} / \mathrm{g}$ with $\mathrm{N}$ rate at $294 \mathrm{mg} / \mathrm{L}$ for leaf weight ratio (LWR), and of $5.14 \mathrm{dm}{ }^{2} / \mathrm{g}$ for specific leaf area (SLA) at $\mathrm{N}$ rate of $378 \mathrm{mg} / \mathrm{L}$.
\end{abstract}

Key Words: Brachiaria brizantha, leaf area ratio, leaf weight ratio, net assimilation rate, relative growth rate, specific leaf area

\section{Introdução}

A produtividade e a perenidade da pastagem decorrem de sua capacidade de reconstituição de nova área foliar, após condições de corte ou de pastejo. Esta capacidade está intrinsecamente associada às condições ambientais, como temperatura, luminosidade, umidade e fertilidade do solo, bem como às características genéticas da planta forrageira, ao manejo da pastagem e à idade fisiológica da planta. As condições do ambiente, associadas ao estado nutricional das plantas e à idade de crescimento, são determinantes no processo de formação e manutenção dos tecidos vegetais e, conseqüentemente, da formação da área foliar.

Segundo Nabinger (1997), entre os fatores limitantes ao aumento do índice de área foliar (IAF), a deficiência de água e de nitrogênio (N) são os mais comuns e promovem a redução da taxa fotossintética das folhas, da interceptação de luz e, conseqüentemente, da área foliar do vegetal.

O fundamento da análise de crescimento é a medida seqüencial da acumulação de matéria orgânica e sua determinação é realizada por meio da avaliação

\footnotetext{
${ }^{1}$ Parte da Dissertação de Mestrado do primeiro autor apresentada à USP/ESALQ, pesquisa apoiada pelo CNPq.

2 Doutorando em Solos e Nutrição de Plantas na USP/ESALQ e pesquisador na Embrapa Cerrados, Caixa Postal 08223, CEP: 73310-970,

Planaltina - DF. E.mail: jdsantos@cpac.embrapa.br

3 Prof. Titular, Depto. de Solos e Nutrição de Plantas, USP/ESALQ, Caixa Postal 09, CEP: 13418-900, Piracicaba - SP. E.mail: famontei@esalq.usp.br. Bolsista CNPq.

${ }^{4}$ Doutorando USP/CENA. Av. Centenário, 303, CEP: 13400-970, Piracicaba-SP. Bolsista da CAPES. E.mail: jlavres@cena.usp.br
} 
do acúmulo de massa seca da planta e do crescimento da área de folhas. Esta determinação é importante porque as folhas são as principais responsáveis pela captação de energia solar e pela produção de matéria orgânica por meio da fotossíntese. Se a superfície foliar e o acúmulo de massa seca da planta são conhecidos, durante certo período de tempo, torna-se possível avaliar a eficiência fotossintética das folhas e sua contribuição para o crescimento da planta (Magalhães, 1985; Benincasa, 1988).

Para o incremento da produção vegetal, é necessário melhor aproveitamento de energia solar e a ação de outros fatores ambientais favoráveis. Todavia, para que a utilização da radiação solar seja eficiente, torna-se necessário que as folhas possuam alta capacidade fotossintética e máximo aproveitamento na captação da energia luminosa (Brown \& Blaser, 1968).

As variações de fatores ambientais, principalmente luz e temperatura, são as maiores responsáveis por mudanças nos valores dos atributos de crescimento. Entre os nutrientes, o $\mathrm{N}$ é o elemento que mais influencia as características de crescimento. Ryle (1970) relatou que o aumento da massa seca de Dactylis glomerata, em resposta a doses de $\mathrm{N}$, decorreu do incremento na taxa de assimilação líquida da planta. Pinto (1993), estudando os capins Panicum maximum cv. Guiné e Setaria anceps cv. Kazungula cultivados em vasos, submetidos a duas doses de $\mathrm{N}$ e avaliados aos 14, 28, 42 e 56 dias após a emergência, constatou que, em ambas as espécies forrageiras, os valores de razão de área foliar (RAF) e razão de massa foliar (RMF) cresceram durante a fase de estabelecimento até a idade de 28 dias, com posterior redução nestes atributos morfológicos. Verificou também que os valores da área foliar específica (AFE), da taxa de assimilação líquida (TAL) e da taxa de crescimento relativo (TCR) apresentaram queda durante o período de crescimento, não observando interação entre as idades de crescimento e as doses de $\mathrm{N}$ utilizadas.

Gomide \& Gomide (1999), trabalhando com três cultivares de Panicum maximum Jacq. (Mombaça, Tanzânia e Vencedor) em seis idades de crescimento, encontraram diferenças nos valores de RAF entre os cultivares aos 17 dias de crescimento, sendo as variações na AFE as principais causas das mudanças na RAF. Os cultivares não diferiram quanto a TAL, mas foram diferentes quanto a TCR na fase inicial de estabelecimento. Posteriormente, aos 24 dias de cres- cimento, equivaleram-se quanto aos valores instantâneos desses atributos de crescimento. Esses autores constataram que o padrão de variação revelou-se elevado nas primeiras semanas, exibindo acentuada queda entre a terceira e quinta semanas e, em seguida, tendeu à estabilidade. Oliveira et al. (2000), em estudo com o objetivo de avaliar o crescimento do Cynodon spp. cv. Tifton 85, em nove idades de crescimento, observaram valores máximos de TCR, TAL, RAF, RMF e AFE, respectivamente, de 0,12 g/g.dia, $6,28 \mathrm{~g} / \mathrm{m}^{2}$.dia, 0,0195 m²/g, 0,59 g/g e $0,0336 \mathrm{~m}^{2} / \mathrm{g}$ aos 14 dias de crescimento e concluíram que a TCR foi mais influenciada pelas variações da RAF em relação à TAL, mas houve efeito mais pronunciado da RMF no comportamento da RAF desta gramínea.

Partindo da hipótese de que as doses de N, as idades de crescimento e/ou a interação entre ambos afetam o crescimento das plantas, neste estudo, objetivou-se analisar o crescimento do capim-marandu (Brachiaria brizantha cv. Marandu) submetido a cinco doses de nitrogênio, em seis idades de crescimento.

\section{Material e Métodos}

O experimento foi conduzido em casa-de-vegetação, no período de 04 de novembro a 30 de dezembro de 2000 na Escola Superior de Agricultura "Luiz de Queiroz” - Universidade de São Paulo, em Piracicaba, Estado de São Paulo.

A espécie Brachiaria brizantha (A. Rich.) Stapf. cv. Marandu foi submetida a cinco doses de $\mathrm{N}$ e avaliada aos 21, 28, 35, 42, 49 e 56 dias de crescimento, após a emergência. As médias e respectivos desvios das temperaturas máxima, mínima e média, durante o período experimental, foram de $39,9 \pm 0,6$; $21,6 \pm 0,3 ; 30,8 \pm 0,4^{\circ} \mathrm{C}$.

As sementes foram colocadas para germinar em recipientes plásticos contendo areia lavada em água corrente e em água desionizada. Vasos plásticos com diâmetro de $17 \mathrm{~cm}$ e capacidade de 3,6 dm 3 foram preenchidos com sílica apresentando granulometria em torno de $3 \mathrm{~mm}$ de diâmetro e livre de impurezas. Seis dias após a emergência, quinze plântulas foram transplantadas para cada vaso, adicionando-se um litro da solução nutritiva correspondente a cada dose em estudo. Foram realizados desbastes periódicos até permanecerem cinco plantas por vaso. As soluções foram circuladas através da sílica com freqüência de três vezes por dia e foram trocadas semanal- 
mente a partir da primeira idade de crescimento. A cada três dias, os vasos foram remanejados dentro de cada bancada, com a finalidade de homogeneização de condições dentro de cada bloco.

Foram utilizadas as doses de $\mathrm{N}$ de 28, 112, 210, 294 e 378 mg/L nas soluções nutritivas, preparadas a partir da solução completa de Sarruge (1975), devidamente modificada para atender as doses de $\mathrm{N}$ utilizadas, com a manutenção da relação $\mathrm{N}-\mathrm{NO}_{3}{ }^{-}: \mathrm{N}^{-\mathrm{NH}_{4}}{ }^{+}$ constante em $70 \%$ de nitrato e $30 \%$ de amônio. O delineamento experimental foi o de blocos completos ao acaso, em arranjo fatorial do tipo $5 \times 6$ (cinco doses de $\mathrm{N}$ e seis idades de crescimento), com quatro repetições.

As coletas foram realizadas nas idades de crescimento de 21, 28, 35, 42, 49 e 56 dias após a emergência. As plantas foram cortadas rentes à superfície do substrato, procedendo-se à coleta da parte aérea e das raízes, que foram separadas da sílica e lavadas com água corrente e água desionizada, utilizando-se duas peneiras de malha com diâmetro de 0,25 e 1,00 mm. O material colhido foi acondicionado em sacos de papel, devidamente identificados, e colocado para secar em estufa com circulação forçada de ar, à temperatura de $65^{\circ} \mathrm{C}$, até atingir peso constante, sendo posteriormente pesado em balança de precisão.

A determinação da área das folhas foi feita por meio de imagens digitalizadas das mesmas, com o auxílio do aplicativo SIARCS (Jorge, 1996). Após 35 dias de idade, por causa da grande quantidade de material, cerca de 30\% das lâminas foliares foram medidas. Os valores totais foram obtidos a partir dos valores da subamostra e sua massa seca com a massa seca total de lâminas foliares de cada unidade experimental.

Os atributos médios de crescimento: taxa de crescimento absoluto (TCA), taxa de crescimento relativo (TCR), taxa de assimilação líquida (TAL), razão de área foliar (RAF), área foliar específica (AFE) e razão de massa foliar (RMF) foram calculados com base nos valores de massa seca total da planta, área foliar total e massa seca das folhas (Radford, 1967).

Os resultados foram submetidos à análise de variância (SAS, 2000). Em função do nível de significância no teste $\mathrm{F}$ para as doses de $\mathrm{N}$ e idades de crescimento, procedeu-se ao estudo de regressão polinomial (superfície de resposta), por intermédio do procedimento estatístico RSREG.

\section{Resultados e Discussão}

Para a taxa de crescimento absoluto (TCA), que representa a velocidade de crescimento do capimmarandu, a interação entre as doses de $\mathrm{N}$ e as idades de crescimento foi significativa $(\mathrm{P}<0,01)$ e se ajustou ao modelo de equação de regressão polinomial (Figura 1). O valor máximo da TCA ocorreu com a dose de $\mathrm{N}$ de 378 mg/L e à idade de 56 dias. Porém, pode-se inferir que este atributo de crescimento atingiria valores mais altos com o emprego de doses mais elevadas de $\mathrm{N}$ na solução e em idades mais avançadas. A menor TCA foi obtida na combinação da mais baixa dose de $\mathrm{N} \mathrm{e}$ menor idade de crescimento. Avaliando-se o aumento do suprimento de $\mathrm{N}$ de 28 para $378 \mathrm{mg} / \mathrm{L}$ e a idade de crescimento de 56 dias, obteve-se acréscimo de 2,8 g/dia, correspondendo a incremento de $311 \%$.

Desse modo, as idades de crescimento tiveram grande efeito quando a dose de $\mathrm{N}$ foi incrementada. Também, Pinto (1993) verificou maior taxa de crescimento absoluto tanto do Panicum maximum cv. Guiné como do capim-setária (Setaria anceps cv. Kazungula), quando cultivado com a dose de $\mathrm{N}$ de $300 \mathrm{mg} / \mathrm{kg}$ de solo, em comparação com a dose de $100 \mathrm{mg} / \mathrm{kg}$ de solo.

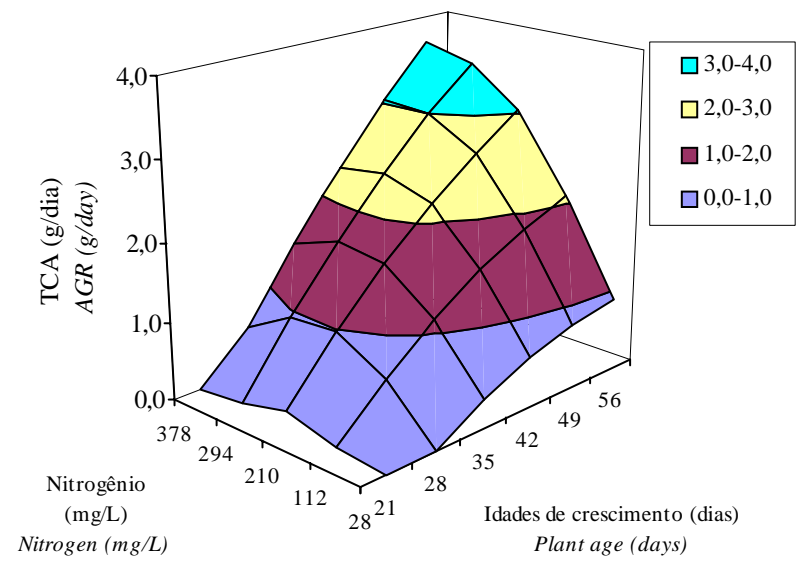

$Y=-2,43870+0,00450 N+0,10190 I+0,00022 N I-0,00002 N^{2}-0,00090 I^{2}$ $\left(R^{2}=0,86\right)$

Figura 1 - Taxa de crescimento absoluto (TCA) do capim-marandu submetido a doses de $\mathrm{N}$, em seis idades de crescimento.

Figure 1 - Absolute growth rate (AGR) of Marandugrass as related to $N$ rates and plant age. 
Para a razão de área foliar (RAF), que representa a área foliar em uso pela planta para produzir um grama de massa seca, foi significativa $(\mathrm{P}<0,01)$ a interação entre as doses de $\mathrm{N}$ e as idades de crescimento. Constatou-se, por meio da equação de regressão polinomial (Figura 2), decréscimo mais pronunciado da RAF, conforme as idades de crescimento, obtido com a dose de $\mathrm{N}$ de $163 \mathrm{mg} / \mathrm{L}$ aos 53 dias. O máximo valor da RAF, aos 21 dias, ocorreu com o suprimento da mais elevada dose de $\mathrm{N}$ na solução (378 mg/L). Tomando-se como referência a dose de N usual da solução completa de Sarruge (1975) de $210 \mathrm{mg} / \mathrm{L}$, a RAF sofreu queda de $1,3 \mathrm{dm}^{2} / \mathrm{g}$, com o avanço das idades de 21 a 56 dias de crescimento. Para o mesmo período de crescimento, porém nas doses de $\mathrm{N}$ de 28 e $378 \mathrm{mg} / \mathrm{L}$, esta redução foi de 0,9 e $1,6 \mathrm{dm}^{2} / \mathrm{g}$, respectivamente.

Queda na RAF, tanto nas doses mais baixas de $\mathrm{N}$, como em idade mais avançada da planta, reflete a diminuição da capacidade fotossintética em relação ao aumento da massa total da planta, o que representa maior custo de respiração e a redistribuição de fotoassimilados para o crescimento da planta (colmo, raízes, perfilhos), em detrimento da produção de folhas, durante o estabelecimento e crescimento do vegetal.

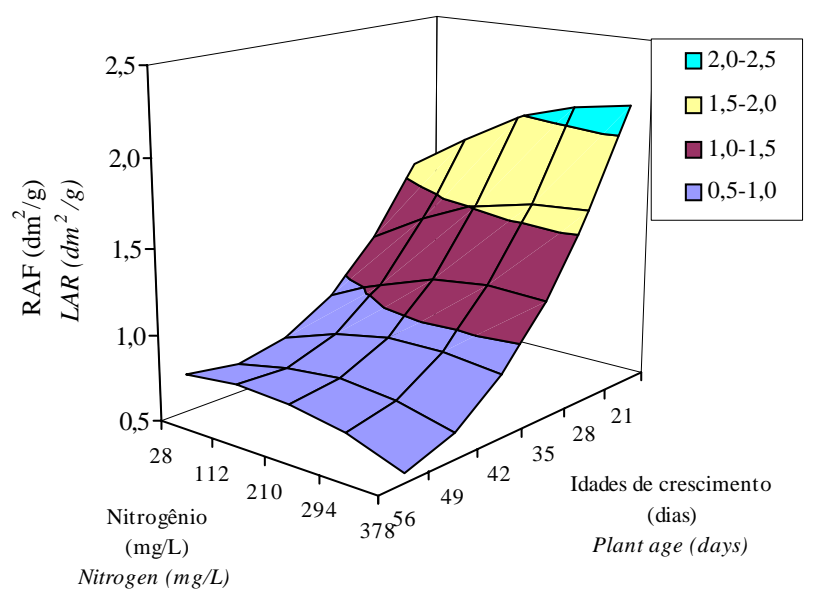

$Y=3,31409+0,00430 \mathrm{~N}-0,11009 \mathrm{I}-0,00006 \mathrm{NI}-0,000003 \mathrm{~N}^{2}+0,\left.00113\right|^{2}$ $\left(R^{2}=0,85\right)$

Figura 2 - Razão de área foliar (RAF) do capim-marandu submetido a doses de $\mathrm{N}$, em seis idades de crescimento.

Figure 2 - Leaf area ratio (LAR) of Marandugrass as related to $N$ rates and plant age.

R. Bras. Zootec., v.33, n.6, p.1985-1991, 2004 (Supl. 2)
Gomide \& Gomide (1999) relataram queda abrupta na RAF entre as idades de 17 e 24 dias para os cultivares Mombaça, Tanzânia e Vencedor. Pinto (1993) observou aumento na RAF dos capins Guiné e Setária até a idade de 28 dias, decrescendo posteriormente sem apresentar significância para as doses de $\mathrm{N}$ (100 e $300 \mathrm{mg} / \mathrm{kg}$ de solo).

As variações em RAF podem ser explicadas pelas alterações de seus componentes - área foliar específica (AFE) e razão de massa foliar (RMF) -, visto que a RAF é o produto da AFE pela RMF. Enquanto a variação na RMF tem efeito direto na produção de massa seca, a variação na AFE contribui indiretamente, via interceptação de luz, para o crescimento da planta (Gomide, 1997).

A área foliar específica (AFE) é o componente morfológico e anatômico da RAF porque relaciona a superfície com a massa seca da própria folha e seu inverso (massa específica da folha) expressa a espessura da folha (Benincasa, 1988).

$\mathrm{A}$ interação entre as doses de $\mathrm{N}$ e as idades de crescimento foi significativa $(\mathrm{P}<0,01)$ para a AFE do capim-marandu. Os valores da AFE desse capim ajustaram-se ao modelo polinomial de regressão, decrescendo com o avanço das idades e com as doses mais elevadas de $\mathrm{N}$ (Figura 3). Verifica-se que a

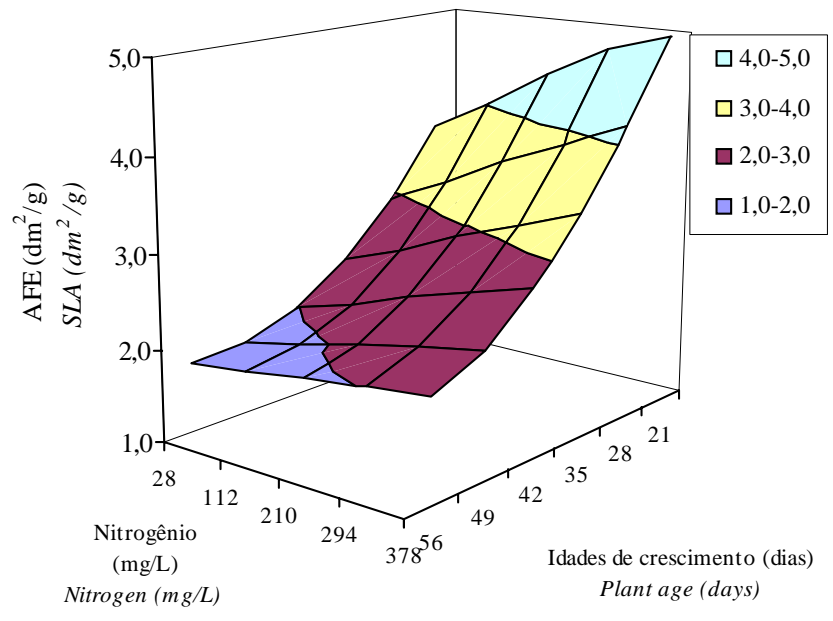

$\mathrm{Y}=6,79163+0,00616 \mathrm{~N}-0,19251 \mathrm{I}-0,00009 \mathrm{NI}-0,000004 \mathrm{~N}^{2}+0,00182 \mathrm{I}^{2}$ $\left(R^{2}=0,84\right)$

Figura 3 - Área foliar específica (AFE) do capim-marandu submetido a doses de $\mathrm{N}$, em seis idades de crescimento.

Figure 3 - Specific leaf area (SLA) of Marandugrass as related to $N$ rates and plant age. 
concentração de $\mathrm{N}$ na solução e a idade de crescimento necessária para alcançarem menor valor foram de $117 \mathrm{mg} / \mathrm{L}$ à idade de 55 dias, enquanto o maior valor da AFE foi obtido aos 21 dias de crescimento, com a mais elevada dose de $\mathrm{N}$. Na combinação da dose mais elevada de $\mathrm{N}$ e idade de crescimento de 21 dias, a AFE do capim-marandu foi $3,1 \mathrm{dm}^{2} / \mathrm{g}$ maior que a obtida com o emprego da mesma dose na idade de 56 dias.

A RAF apresentou maiores coeficientes de correlação com a AFE do que com a RMF (Tabela 1) em cada dose de $\mathrm{N}$, sendo este o fator que mais influenciou a queda da RAF, corroborando os resultados de Pinto (1993). Gomide \& Gomide (1999) verificaram que as variações observadas para a RAF decorreram dos valores de AFE, que variaram linear e negativamente com a idade dos capins Mombaça, Tanzânia e Vencedor e indicaram aumento da espessura da folha com o avanço das idades de crescimento. Gomide (1996) estudou cinco cultivares de Cynodon dactylon e verificou que a AFE variou em função da idade, atingindo valor máximo de $2,3 \mathrm{dm}^{2} / g$ aos 28 dias e decrescendo até o valor de $1,5 \mathrm{dm}^{2} / \mathrm{g}$ aos 84 dias de crescimento.

Altos valores de AFE podem ocorrer em plantas sob baixa intensidade luminosa e/ou cultivadas em solos férteis. Em solos de baixa fertilidade, a cultura desenvolve pouca área foliar e, portanto, menos biomassa, e, graças à alocação preferencial de carbono para o sistema radicular, resulta em valores mais baixos de RMF (Gomide, 1997).

Considerando-se que as folhas são os órgãos responsáveis pela produção de massa seca a partir da fotossíntese e que as demais partes da planta depen-

Tabela 1 - Coeficiente de correlação entre RAF e AFE ou $\mathrm{RMF}$, em cada uma das cinco doses de $\mathrm{N}$

Table 1 - Correlation coefficient between LAR and SLA or $L W R$, on each of five $N$ rates

\begin{tabular}{|c|c|c|c|c|c|}
\hline & \multicolumn{5}{|c|}{$\begin{array}{c}\text { Doses de } \mathrm{N}(\mathrm{mg} / \mathrm{L}) \\
\quad N \text { rates }(\mathrm{mg} / \mathrm{L})\end{array}$} \\
\hline & 28 & 112 & 210 & 294 & 378 \\
\hline $\begin{array}{l}\text { AFE } \\
S L A\end{array}$ & $0,94^{* *}$ & $0,98^{* *}$ & $0,98^{* *}$ & $0,99^{* *}$ & $0,99^{* *}$ \\
\hline $\begin{array}{l}\text { RMF } \\
L W R\end{array}$ & $0,70^{* *}$ & $0,34^{\mathrm{ns}}$ & $0,84^{* *}$ & $0,83^{* *}$ & $0,79^{* *}$ \\
\hline
\end{tabular}

dem da exportação de fotoassimilados produzidos nas folhas, a RMF expressa a fração de massa seca não exportada das folhas para essas outras partes da planta (Benincasa, 1988).

Para a RMF a interação entre as doses de $\mathrm{N}$ e as idades de crescimento foi significativa $(\mathrm{P}<0,01)$. $\mathrm{Na}$ Figura 4, verifica-se que, com o avanço das idades de crescimento, associadas à mais elevada dose de $\mathrm{N}$, a RMF sofreu redução de 0,48 e 0,38 g/g, respectivamente, aos 21 e 56 dias de crescimento. Para as demais doses de $\mathrm{N}$, nota-se redução contínua da RMF até os 42 dias de crescimento, mantendo-se praticamente constante até a idade de 56 dias.

$\mathrm{O}$ incremento nas doses de $\mathrm{N}$ proporcionou retenção do material fotossintetizado nas folhas, as quais constituem a fração mais importante para a alimentação animal. Por outro lado, em condições de deficiência de $\mathrm{N}$, as folhas exportam mais fotossintetatos às raízes que aquelas supridas adequadamente com $\mathrm{N}$.

Oliveira et al. (2000), estudando o capim-tifton 85, quanto aos índices de crescimento, avaliado em nove idades, constataram que os valores da RMF sofreram redução exponencial, variando entre 0,59 e $0,27 \mathrm{~g} / \mathrm{g}$ no período de 14 a 70 dias de rebrota, respectivamente.

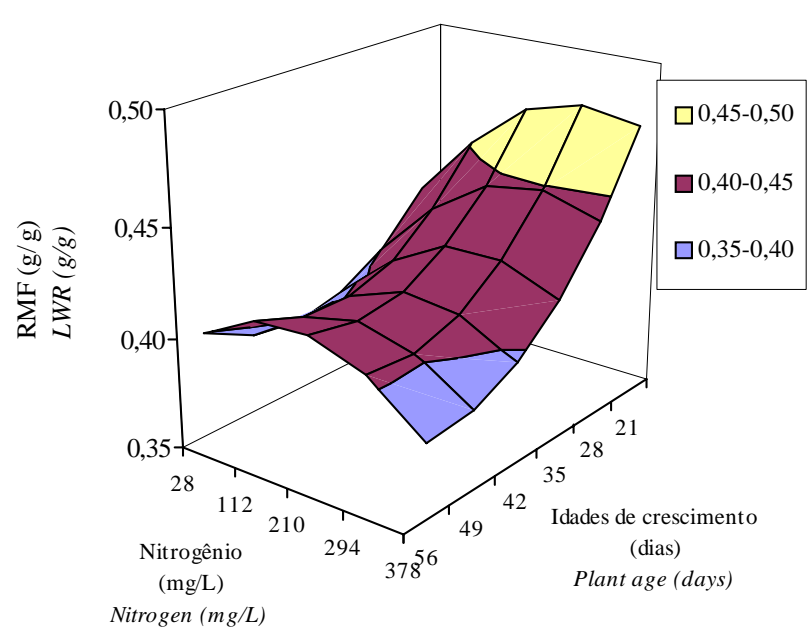

$Y=0,51941+0,00057 \mathrm{~N}-0,00697 \mathrm{I}-0,000006 \mathrm{NI}-0,0000007 \mathrm{~N}^{2}+0,00008 \mathrm{I}^{2}$ $\left(R^{2}=0,50\right)$

Figura 4 - Razão de massa foliar (RMF) do capimmarandu submetido a doses de $\mathrm{N}$, em seis idades de crescimento.

Figure 4 - Leaf weight ratio ( $L W R$ ) of Marandugrass as related to $N$ rates and plant ages.

R. Bras. Zootec., v.33, n.6, p.1985-1991, 2004 (Supl. 2) 
As estimativas da taxa de assimilação líquida (TAL) média não revelaram interação significativa $(\mathrm{P}>0,05)$ entre as doses de $\mathrm{N}$ e as idades de crescimento, sendo somente influenciadas $(\mathrm{P}<0,01)$ pelas idades de crescimento. A TAL média estimada decresceu linearmente de 14,1 e 7,5 g/ $\mathrm{m}^{2}$.dia com o avanço nas idades de crescimento de 28 para 56 dias, de acordo com a equação $\mathrm{Y}=20,646$ - 0,2349X $\left(\mathrm{R}^{2}=0,99\right)$. O comportamento e os valores da TAL do capim-marandu estão de acordo com os relatados por Pinto (1993) para o capim-guiné e Oliveira et al. (2000), para o capim-tifton 85.

A partição de carbono para outras partes da planta, exceto as folhas, pode ser verificada pela queda da RAF (Figura 2), proporcionando o acúmulo de massa seca em outros órgãos vegetais não-fotossintetizantes, como raízes e colmo, e concorre para o aumento das perdas respiratórias. Assim, a área foliar, embora crescente, deve suprir, além de suas próprias perdas respiratórias (que também aumentam), as crescentes perdas respiratórias de toda a planta (Gomide, 1997).

Para os resultados da taxa de crescimento relativo (TCR) do capim-marandu, foi significativa $(\mathrm{P}<0,01)$ a interação entre as doses de $\mathrm{N}$ e as idades de crescimento (Figura 5). Os valores da TCR ajustaram-se ao modelo polinomial de regressão, que

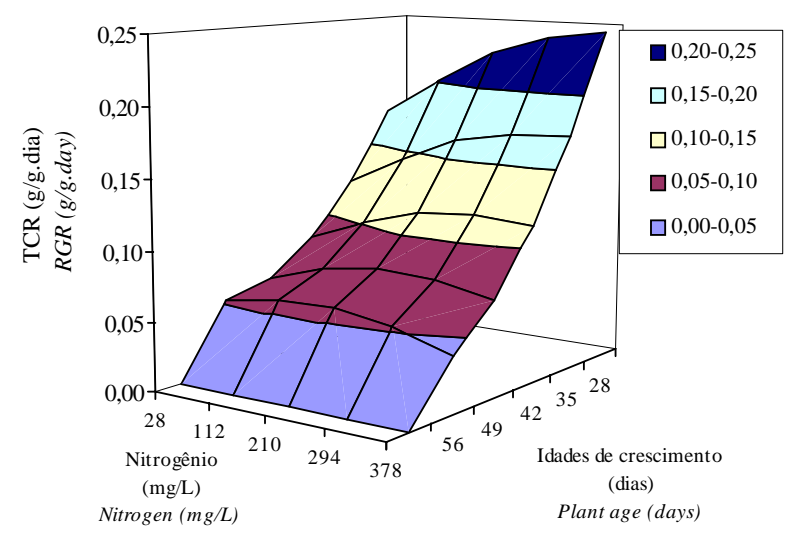

$Y=0,51422+0,00062 \mathrm{~N}-0,01666 \mathrm{I}-0,000008 \mathrm{NI}-0,0000004 \mathrm{~N}^{2}+0,\left.00015\right|^{2}$ $\left(R^{2}=0,93\right)$

Figura 5 - Taxa de crescimento relativo (TCR) do capimmarandu submetido a doses de $\mathrm{N}$, em seis idades de crescimento.

Figure 5 - Relative growth rate (RGR) of Marandugrass as related to $N$ rates and plant age. proporcionou a mínima TCR aos 56 dias, para todas as doses de N. Constatou-se também que, com o avanço das idades de crescimento combinadas com a dose de $\mathrm{N}$ de 378 mg/L, houve redução acentuada da TCR da gramínea forrageira. Na idade de 56 dias, os valores de TCR mantiveram-se praticamente constantes com o aumento das doses de $\mathrm{N}$ na solução nutritiva.

A principal razão do acréscimo da TCR está no aumento da RAF e não da TAL, pois esta não foi influenciada pelas doses de N. Esses resultados diferem dos relatos de Ryle (1970) e de Van Der Werf et al. (1993). Entretanto, Glimskär \& Ericsson (1999), em estudo com cinco espécies forrageiras (Agrostis capillaris, Crepis praemorsa, Dactylis glomerata, Danthonia decumbens e Polygala vulgaris), relataram que a redução de $50 \%$ na disponibilidade de $\mathrm{N}$ ocasionou queda de $50 \%$ na RAF, que foi significativamente correlacionada com a TCR, enquanto a TAL não variou com as doses de $\mathrm{N}$. Andrade et al. (2002) relataram, ao trabalharem com capim-elefante (Pennisetum purpureum Schum. cv. Napier), valores médios de TCR, TAL e RAF de 0,0083 g/g.dia, $3,57 \mathrm{~g} / \mathrm{cm}^{2}$.dia e $0,0021 \mathrm{~m}^{2} / \mathrm{g}$, respectivamente, atribuindo o baixo valor encontrado de TCR ao fato de este ter sido calculado como um valor médio ao longo do período experimental (123 dias). A TAL mais expressiva foi obtida nas maiores doses de combinações de N e potássio. A menor disponibilidade de $\mathrm{N}$ pode ter afetado a fotossíntese, em razão de o $\mathrm{N}$ ser constituinte da molécula da clorofila e fazer parte das estruturas moleculares de todo o aparato protéico envolvido no processo fotossintético, o que diminuiu significativamente a TAL (Andrade et al., 2002).

Paciullo et al. (1998), estudando Pennisetum purpureum Schum. cv. Mott, encontraram efeito de doses de $\mathrm{N}$ na TAL somente para altura de corte de $120 \mathrm{~cm}$, não observando esse efeito nesse capim manejado à altura de corte de $80 \mathrm{~cm}$.

Os resultados referentes a TAL obtidos em várias espécies são contraditórios e devem ser cuidadosamente analisados. A taxa fotossintética da cultura não é necessariamente uma função direta de sua área foliar, visto a contribuição desigual de folhas de diversas idades e os atributos morfológicos, como ângulo de disposição de folhas, que interferem na interceptação luminosa. Desse modo, duas plantas com a mesma área de folhas podem interceptar mais ou menos luz, variando sua TAL, em função do ângulo de inserção das folhas.

R. Bras. Zootec., v.33, n.6, p.1985-1991, 2004 (Supl. 2) 
Pinto (1993) estimou a TCR máxima do capimguiné aos 14 dias de crescimento de 0,20 g/g.dia, a qual decresceu em pequena magnitude até os 28 dias e mais acentuadamente até os 42 dias de idade. Quanto à TCR do capim-tifton 85, Oliveira et al. (2000) observaram variação exponencial, com valores de 0,12 a $0,026 \mathrm{~g} / \mathrm{g}$.dia, dos 14 aos 70 dias, apresentando queda mais acentuada até a idade de 35 dias. Verificaram também que a TCR apresentou correlação positiva com a TAL $(r=0,77)$ e RAF $(r=0,94)$, concluindo que a TCR foi mais influenciada pelas variações na RAF.

\section{Conclusões}

O crescimento do capim-marandu foi influenciado pela idade fisiológica em que as plantas foram colhidas e pelas concentrações de $\mathrm{N}$ no substrato. As doses de $\mathrm{N}$ e as idades de crescimento interagiram nos atributos taxa de crescimento absoluto, razão de área foliar, razão de massa foliar, área foliar específica e taxa de crescimento relativo, enquanto, para a taxa de assimilação líquida, isto não ocorreu. As doses de $\mathrm{N}$ foram mais efetivas que as idades de crescimento em promover ou permitir ajustes morfológicos e fisiológicos da planta, resultando em respostas máximas e mais rápidas nas variáveis avaliadas.

\section{Literatura Citada}

ANDRADE, A.C.; FONSECA, D.M.; LOPES, R.S. et al. Análise de crescimento do capim-elefante napier adubado e irrigado. In: REUNIÃO ANUAL DA SOCIEDADE BRASILEIRA DE ZOOTECNIA, 39., 2002, Recife. Anais... Recife: Sociedade Brasileira de Zootecnia, 2002. CD-ROM. Forragicultura.

BENINCASA, M.M.P. Análise de crescimento de plantas: noções básicas. Jaboticabal: Fundação de Estudos e Pesquisas em Agronomia, Medicina Veterinária e Zootecnia, 1988. 41p.

BROWN, R.H.; BLASER, R.E. Leaf area index in pasture growth. Herbage Abstract, v.38, p.1-9, 1968.

GLIMSKÄR, A.; ERICSSON, T. Relative nitrogen limitation at steady-state nutrition as a determinant of plasticity in five grassland plant species. Annals of Botany, v.84, p.413-420, 1999.

GOMIDE, C.C.C. Algumas características fisiológicas e químicas de cinco cultivares de Cynodon. Jaboticabal: Universidade Estadual Paulista, 1996. 100p. Dissertação (Mestrado em Zootecnia) - Universidade Estadual Paulista, 1996.
GOMIDE, J.A. Morfogênese e análise de crescimento de gramíneas tropicais. In: SIMPÓSIO INTERNACIONAL SOBRE PRODUÇÃO ANIMAL EM PASTEJO, 1997, Viçosa, MG. Anais... Viçosa, MG: Universidade Federal de Viçosa, 1997. p.411-430.

GOMIDE, C.A.M.; GOMIDE, J.A. Análise de crescimento de cultivares de Panicum maximum Jacq.. Revista Brasileira de Zootecnia, v.28, p.675-680, 1999.

JORGE, L.A.C. Recomendações práticas para a aquisição de imagens digitais analisadas através do SIARCS. EMBRAPA - Instrumentação Agropecuária, São Carlos, não paginado. 1996 (Circular Técnica, 01).

MAGALHÃES, A.C.N. Análise quantitativa do crescimento. In: FERRI, M.G. (Ed.). Fisiologia vegetal. São Paulo: Universidade de São Paulo, 1985. v.1, p.332-349.

NABINGER, C. Eficiência do uso de pastagens: disponibilidade e perdas de forragem. In: SIMPÓSIO SOBRE MANEJO DA PASTAGEM, 14., 1997, Piracicaba. Anais... Piracicaba: Fundação de Estudos Agrários “Luiz de Queiroz”, 1997. p.213-251.

OLIVEIRA, M.A.; PEREIRA, O.G.; GOMIDE, J.A. et al. Análise de crescimento do capim-bermuda "Tifton 85" (Cynodon spp.). Revista Brasileira de Zootecnia, v.29, p.1930-1938, 2000 (Suplemento 1).

PACIULLO, D.S.C.; GOMIDE, J.A.; RIBEIRO, K.G. Adubação nitrogenada do capim-elefante cv. Mott. 1. Rendimento forrageiro e características morfofisiológicas ao atingir 80 e $120 \mathrm{~cm}$ de altura. Revista Brasileira de Zootecnia, v.27, p.1069-1075, 1998.

PINTO, J.C. Crescimento e desenvolvimento de Andropogon gayanus, Panicum maximum e Setaria anceps cultivadas em vasos, sob diferentes doses de nitrogênio. Viçosa, MG: Universidade Federal de Viçosa, 1993. 149p. Tese (Doutorado em Zootecnia) - Universidade Federal de Viçosa, 1993.

RADFORD, P.J. Growth analysis formulae - their use and abuse. Crop Science, v.18, p.171-175, 1967.

RYLE, G.J.A. Effects of two levels of applied nitrogen on the growth of $\mathrm{S}_{37}$ cocksfoot in small simulated swards in a controlled environment. Journal of the British Grassland Society, v.25, p.20-29, 1970.

SARRUGE, J.R. Soluções nutritivas. Summa Phytopathologica, v.1, p.231-233, 1975.

STATISTICAL ANALYSES SYSTEM - SAS. SAS/STAT. User's guide. version 8.0. Cary: 2000.

Van Der WERF, A.; Van NUENEN, M.; VISSER, A.J. et al. Contribution of physiological and morphological plant traits to a species competitive ability at high and low nitrogen supply. A hypothesis for inherent fast and slow-growing monocotyledonous species. Oecologia, v.94, p.434-440, 1993.
Recebido em: 15/04/03 Aceito em: 09/07/04 